\title{
Transformation through Communication System the Step in Sugar Industries Domain
}

\author{
Pratibha M. Deshmukh ${ }^{1}$, Dr. Pallavi P. Jamsandekar ${ }^{2}$ \\ Assistant Professor, MCA, BVIMIT, Navi Mumbai, India ${ }^{1}$ \\ Professor, MCA, BVIMRDA, Sangli, India ${ }^{2}$
}

\begin{abstract}
Now a day's Sugar Industries are facing many social problems to run day to day activities. The main difficulties found in fixing cane prices, sugar prices, various taxes, short crushing period and competition with Khandasari and gur products etc. These problems can be minimized only if total cost is decreased and improvement in cane production. However new technology can support to bring minimization in total cost. This paper aims to study existing ICT (Information and Communication System) associated with communication system in between stakeholders and suggested the solution step towards transformation through communication system in Sugar Industries Domain.
\end{abstract}

Keywords: Social Problems, ICT, Transformation, Sugar Industries Domain, Communication System

\section{INTRODUCTION}

India is the second largest producer of sugar production all over the globe, with more than 45 millions of sugar cane growers are in the country. Most of the rural population in India depends on these industries followed by the textile industry. This industry in India is well maintained and day by day growing at a steady state. It provides direct employment to nearly 5 lakh people of India. [1]

Information and Communication Technology (ICT) is used to refer as an infrastructure, product and services development that facilitate the gathering, storing, updating and investigating information that may be channelized further for decision making. Computer and information technologies are expected to bring about the production and social interactions in the new economy, Accounting, Engineering Management, Process Evaluation and Planning, Project Design Evaluation and Planning. ICT is enabled for information self-service, enterprise access, data quality, performance management, business productivity, customer service, cost effectiveness, increase in accuracy etc. All Sugar Industries required basic infrastructural elements creating their ICT platform to perform the transactions using hardware, software and network.

Proper use of ICT for communication in between stakeholders is desired for every organization. Because it has influence on total cost and productivity. If it used systematically it has strengths to save time and cost, ultimately positive effect on total cost in case of Sugar Industry.

\section{OBJECTIVES}

1. To understand existing communication system in Sugar Industries domain.

2. To suggest standard approach for communication system in Sugar Industries.

\section{HYPOTHESIS}

Hypothesis 1: No standard method is used for communicating and collecting information required inside Sugar Factory. Hypothesis 2: Official email Id will have greater impact on communication system of Sugar Factories.

\section{RESEARCH METHODOLOGY}

This paper is based on primary data collection and author has been gathered the primary data for her PhD research work. The primary data is collected from 30 Sugar Factories categorised in 3 capacities in TCD (Tons of Cane per Day) of small capacity (1250-2500), medium capacity (2501-4000) and large capacity (4001-9000), along with 148 respondents including the managerial users those are working in various departments except computer/IT department and technical users from Information Technology department of Sugar Industries in Western Maharashtra. The gathered data is organized and analysed systematically by using Statistical Package for the Social Sciences (SPSS) Tool. 
Vol. 8, Issue 5, May 2019

\section{DATA ANALYSIS AND INTERPRETATION}

1. Do you have any computerized system to maintain the events, activities, invitation, meetings \& work schedules?

\begin{tabular}{|l|l|l|l|l|l|}
\hline \multicolumn{2}{|c|}{} & \multicolumn{3}{|c|}{ Capacity } & Total \\
\cline { 3 - 6 } \multicolumn{2}{|c|}{} & $1250-2500$ & $2501-4000$ & $4001-9000$ & \\
\hline \multirow{2}{*}{ Yes } & Count & 4 & 0 & 1 & 5 \\
\cline { 2 - 6 } & $\%$ within Capacity & $5 \%$ & $0.0 \%$ & $2.5 \%$ & $4.2 \%$ \\
\hline \multirow{2}{*}{ No } & Count & 38 & 38 & 39 & 115 \\
\cline { 2 - 6 } & $\%$ within Capacity & $90.5 \%$ & $100.0 \%$ & $97.5 \%$ & $95.8 \%$ \\
\hline \multirow{2}{*}{ Total } & Count & 42 & 38 & 40 & 120 \\
\cline { 2 - 6 } & $\%$ within Capacity & $100.0 \%$ & $100.0 \%$ & $100.0 \%$ & $100.0 \%$ \\
\hline
\end{tabular}

Chi-Square Tests

\begin{tabular}{|l|l|l|l|}
\hline & Value & df & Asymp. Sig. (2-sided) \\
\hline Pearson Chi-Square & $4.949^{\mathrm{a}}$ & 2 & .084 \\
\hline Likelihood Ratio & 5.799 & 2 & .055 \\
\hline Linear-by-Linear Association & 2.577 & 1 & .108 \\
\hline N of Valid Cases & 120 & & \\
\hline
\end{tabular}

The above table shows there is no significant difference between the sugar factories and the computerized system to maintain the events, activities, invitation, meetings \& work schedules. Very less responses received from small capacity $(9.5 \%)$, medium capacity $(0.0 \%)$ and large capacity $(2.5 \%)$ users have responded that they have computerized system to maintain the events, activities, invitation, meetings \& work schedules. From small capacity $(90.5 \%)$, medium capacity $(100.0 \%)$ and large capacity (97.5\%) users have responded that they don't have computerized system to maintain the events, activities, invitation, meetings \& work schedules. It indicates that till today there is no an ICT solution exist to maintain the events, activities, invitation, meetings \& work schedules. This might be because there is no complete solution exist due to no support from management, they don't want to adopt new technologies and might be cost issues.

2. Do you have any SMS system?

\begin{tabular}{|l|l|l|l|l|l|}
\hline \multicolumn{2}{|c|}{} & \multicolumn{3}{|c|}{ Capacity } & Total \\
\cline { 3 - 6 } \multicolumn{2}{|c|}{} & $1250-2500$ & $2501-4000$ & $4001-9000$ & \\
\hline \multirow{2}{*}{ Yes } & Count & 33 & 38 & 23 & 94 \\
\cline { 2 - 6 } & $\%$ within Capacity & $78.6 \%$ & $97.4 \%$ & $52.3 \%$ & $75.2 \%$ \\
\hline \multirow{2}{*}{ No } & Count & 9 & 1 & 21 & 31 \\
\cline { 2 - 6 } & $\%$ within Capacity & $21.4 \%$ & $2.6 \%$ & $47.7 \%$ & $24.8 \%$ \\
\hline \multirow{2}{*}{ Total } & Count & 42 & 39 & 44 & 125 \\
\cline { 2 - 6 } & $\%$ within Capacity & $100.0 \%$ & $100.0 \%$ & $100.0 \%$ & $100.0 \%$ \\
\hline
\end{tabular}

Chi-Square Tests
\begin{tabular}{|l|l|l|l|}
\hline & Value & df & Asymp. Sig. (2-sided) \\
\hline Pearson Chi-Square & $22.997^{\mathrm{a}}$ & 2 & .000 \\
\hline Likelihood Ratio & 26.180 & 2 & .000 \\
\hline Linear-by-Linear Association & 8.188 & 1 & .004 \\
\hline N of Valid Cases & 125 & & \\
\hline
\end{tabular}

The above table shows there is significant difference between the sugar factories and the availability of computerized SMS system (Chi-square $=22.997, \mathrm{df}=2, \mathrm{P}=.000)$. As compared with medium capacity $(97.4 \%)$ large capacity $(52.3 \%)$ of sugar industries have less facility of SMS system and As compared with small capacity (97.4\%) large capacity $(52.3 \%)$ of sugar industries have also less facility of SMS system. It indicates that till today there is no SMS system is executed in all large capacity Sugar Factories. This might be because their IT department is not taking interest in initiating SMS system or higher administration is not allowing for the same. 
Vol. 8, Issue 5, May 2019

3. Do you get notifications, circulars on your sugar factory web portal?

\begin{tabular}{|l|l|l|l|l|l|}
\hline \multicolumn{2}{|c|}{} & \multicolumn{3}{|c|}{ Capacity } & \multirow{2}{*}{ Total } \\
\cline { 3 - 6 } \multicolumn{2}{c|}{} & $1250-2500$ & $2501-4000$ & $4001-9000$ & \\
\hline \multirow{2}{*}{ Yes } & Count & 8 & 4 & 2 & 14 \\
\cline { 2 - 6 } & $\%$ within Capacity & $16.7 \%$ & $10.5 \%$ & $5.0 \%$ & $11.1 \%$ \\
\hline \multirow{2}{*}{ No } & Count & 40 & 34 & 38 & 112 \\
\cline { 2 - 6 } & $\%$ within Capacity & $83.3 \%$ & $89.5 \%$ & $95.0 \%$ & $88.9 \%$ \\
\hline \multirow{2}{*}{ Total } & Count & 48 & 38 & 40 & 126 \\
\cline { 2 - 6 } & $\%$ within Capacity & $100.0 \%$ & $100.0 \%$ & $100.0 \%$ & $100.0 \%$ \\
\hline
\end{tabular}

Chi-Square Tests

\begin{tabular}{|l|l|l|l|}
\hline & Value & Df & Asymp. Sig. (2-sided) \\
\hline Pearson Chi-Square & $3.026^{\mathrm{a}}$ & 2 & .220 \\
\hline Likelihood Ratio & 3.197 & 2 & .202 \\
\hline Linear-by-Linear Association & 2.999 & 1 & .083 \\
\hline N of Valid Cases & 126 & & \\
\hline
\end{tabular}

The above table shows there is no significant difference between the sugar factories and notifications, circulars availability on the web portal of sugar factories (Chi-square=3.026, $\mathrm{df}=2, \mathrm{P}=.220$ ). From above statistics it shows that small capacity $(83.3 \%)$, medium capacity $(89.5 \%)$ and large capacity $(95.0 \%)$ users have responded that they don't get notifications and circulars on sugar factory web portal. Total $88.9 \%$ users have responded no notifications and circulars available on sugar factory web portal. This might be because sugar factories administration is still following conventional methods for the same. They are not aware the advantages of such online communication system.

4. Does the sugar factory transmit/receive data to/from other sugar factory?

\begin{tabular}{|l|l|l|l|l|l|}
\hline \multicolumn{2}{|c|}{} & \multicolumn{2}{|c|}{ Capacity } & \multirow{2}{*}{ Total } \\
\cline { 3 - 6 } \multicolumn{2}{c|}{} & $1250-2500$ & $2501-4000$ & $4001-9000$ & \\
\hline \multirow{2}{*}{ Yes } & Count & 11 & 14 & 11 & 36 \\
\cline { 2 - 6 } & $\%$ within Capacity & $18.3 \%$ & $35.0 \%$ & $23.9 \%$ & $24.7 \%$ \\
\hline \multirow{2}{*}{ No } & Count & 49 & 26 & 35 & 110 \\
\cline { 2 - 6 } & $\%$ within Capacity & $81.7 \%$ & $65.0 \%$ & $76.1 \%$ & $75.3 \%$ \\
\hline \multirow{2}{*}{ Total } & Count & 60 & 40 & 46 & 146 \\
\cline { 2 - 6 } & $\%$ within Capacity & $100.0 \%$ & $100.0 \%$ & $100.0 \%$ & $100.0 \%$ \\
\hline
\end{tabular}

Chi-Square Tests
\begin{tabular}{|l|l|l|l|}
\hline \multicolumn{1}{|c|}{ Value } & df & Asymp. Sig. (2-sided) \\
\hline Pearson Chi-Square & $3.609^{\mathrm{a}}$ & 2 & .165 \\
\hline Likelihood Ratio & 3.522 & 2 & .172 \\
\hline Linear-by-Linear Association & .609 & 1 & .435 \\
\hline N of Valid Cases & 146 & & \\
\hline
\end{tabular}

The above table shows the sugar factory transmit data to/from other sugar factories. There is no significant difference between sugar factories of small capacity, medium capacity and large capacity (Chi square=3.609, df=2, P=.165). Out of this $24.7 \%$ users are positive and $75.3 \%$ users are negative towards transmission receiving inter factory data.

5. How sugar factory transmit/receive data to/from other sugar factory?

\begin{tabular}{|l|l|l|l|l|l|l|l|l|}
\hline \multirow{2}{*}{} & \multicolumn{9}{|c|}{ Capacity } \\
\cline { 2 - 9 } & \multicolumn{2}{|c|}{$1250-2500$} & \multicolumn{2}{c|}{$2501-4000$} & \multicolumn{2}{c|}{$4001-9000$} & \multicolumn{2}{c|}{ Total } \\
\cline { 2 - 9 } & Count & Column N \% & Count & Column N \% & Count & Column N \% & Count & Column N \% \\
\hline 1 Email & 27 & $96.4 \%$ & 23 & $100.0 \%$ & 36 & $100.0 \%$ & 86 & $98.9 \%$ \\
2 Whatsapp & 4 & $14.3 \%$ & 7 & $30.4 \%$ & 1 & $2.8 \%$ & 12 & $13.8 \%$ \\
3 Through Website & 1 & $3.6 \%$ & 0 & $0.0 \%$ & 1 & $2.8 \%$ & 2 & $2.3 \%$ \\
Total & 28 & $100.0 \%$ & 23 & $100.0 \%$ & 36 & $100.0 \%$ & 87 & $100.0 \%$ \\
\hline
\end{tabular}


Vol. 8, Issue 5, May 2019

Pearson Chi-Square Tests

\begin{tabular}{|cc|c|}
\hline & Capacity \\
\hline $\begin{array}{c}\text { If yes then select the } \\
\text { following which is }\end{array}$ & Chi-square & 11.948 \\
applicable & Df & 6 \\
\hline
\end{tabular}

Comparisons of Column Proportions ${ }^{b}$

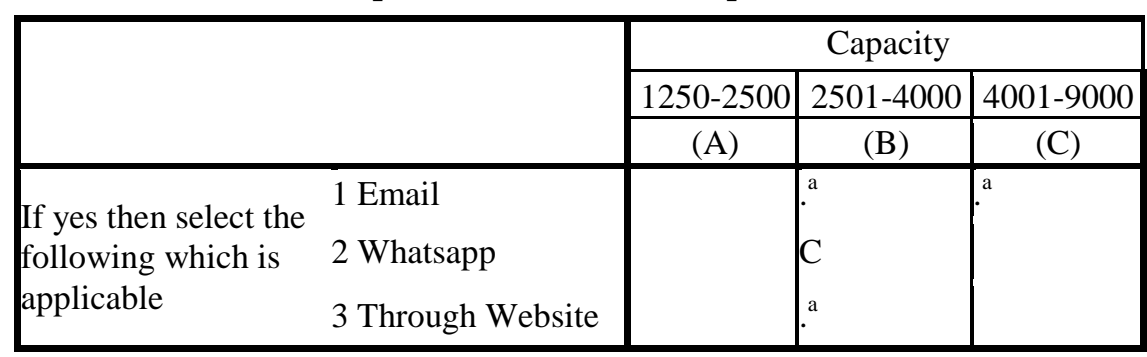

The above table shows the methods of transmitting data from one Sugar Factory to another. Use of whatsapp is more (30.4\%) by factories having medium capacity as compared to factories with large capacity (2.8\%). A Pearson ChiSquare Tests indicates that there is a significant difference in transmitting information from one Sugar Factory to another. (Chi- square $=11.948, \mathrm{df}=6, \mathrm{p}=0.063$ ). However, above said statistical analysis indicates that medium capacity Sugar Factories Administration stakeholders are more comfortable with use of Whatsapp for sharing information to other Sugar Factories.

6. How do you communicate for collecting the information required inside the sugar factory?

\begin{tabular}{|c|c|c|c|c|c|c|c|c|}
\hline & \multicolumn{8}{|c|}{ Capacity } \\
\hline & \multicolumn{2}{|c|}{$1250-2500$} & \multicolumn{2}{|c|}{$2501-4000$} & \multicolumn{2}{|c|}{ 4001-9000 } & \multicolumn{2}{|l|}{ Total } \\
\hline & Count & Column N \% & Count & Column N \% & Count & Column N \% & Count & Column N \% \\
\hline 1 Whatsapp & 12 & $25.5 \%$ & 7 & $19.4 \%$ & 3 & $7.1 \%$ & 22 & $17.6 \%$ \\
\hline 2 Chat & 2 & $4.3 \%$ & 0 & $0.0 \%$ & 0 & $0.0 \%$ & 2 & $1.6 \%$ \\
\hline 3 Telephonic & 34 & $72.3 \%$ & 34 & $94.4 \%$ & 35 & $83.3 \%$ & 103 & $82.4 \%$ \\
\hline 4 SMS & 8 & $17.0 \%$ & 4 & $11.1 \%$ & 5 & $11.9 \%$ & 17 & $13.6 \%$ \\
\hline 5 Email & 29 & $61.7 \%$ & 25 & $69.4 \%$ & 35 & $83.3 \%$ & 89 & $71.2 \%$ \\
\hline Total & 47 & $100.0 \%$ & 36 & $100.0 \%$ & 42 & $100.0 \%$ & 125 & $100.0 \%$ \\
\hline
\end{tabular}

Pearson Chi-Square Tests

\begin{tabular}{|c|c|c|}
\hline & & Capacity \\
\hline \multirow{3}{*}{$\begin{array}{l}\text { How do you communicate for } \\
\text { collecting the information } \\
\text { required inside the sugar } \\
\text { factory }\end{array}$} & Chi-square & 21.467 \\
\hline & Df & 10 \\
\hline & Sig. & $.018^{*, b, c}$ \\
\hline
\end{tabular}

Comparisons of Column Proportions ${ }^{\mathrm{b}}$

\begin{tabular}{|c|c|c|c|c|}
\hline & & \multicolumn{3}{|c|}{ Capacity } \\
\hline & & $1250-2500$ & $2501-4000$ & $4001-9000$ \\
\hline & & (A) & (B) & (C) \\
\hline $\begin{array}{l}\text { How do you communicate for } \\
\text { collecting the information } \\
\text { required inside the sugar factory }\end{array}$ & $\begin{array}{l}1 \text { Whatsapp } \\
2 \text { Chat } \\
3 \text { Telephonic } \\
4 \text { SMS } \\
5 \text { Email }\end{array}$ & & $\dot{a}^{\mathrm{a}}$ &.$^{\mathrm{a}}$ \\
\hline
\end{tabular}


Vol. 8, Issue 5, May 2019

Hypothesis 1: No standard method is used for communicating and collecting information required inside Sugar Factory. The above table shows that there is a significant difference to communicate for information inside Sugar Factory of different capacity (Chi- square $=21.467, \mathrm{df}=10, \mathrm{p}=0.018$ ). However, above said statistical analysis indicates that medium capacity (94.5\%) Sugar Factories Administration is having more telephonic communication as compare with small capacity $(72.3 \%)$ inside their Sugar Factory. Oral communication may find difficulties in compliance of day to day activities. Use of standard method is must for collecting information. There is no official proof or document or log is maintained for sharing required information. Therefore hypothesis $\mathrm{C} 1$ is accepted.

7. Do you have any department wise email id system for internal communication?

\begin{tabular}{|l|l|l|l|l|l|}
\hline \multicolumn{2}{|c|}{} & \multicolumn{2}{|l|}{ Capacity } & \multirow{2}{*}{ Total } \\
\cline { 3 - 6 } \multicolumn{2}{c|}{$1250-2500$} & $2501-4000$ & $4001-9000$ & \\
\hline \multirow{2}{*}{ Yes } & Count & 11 & 24 & 37 & 72 \\
\cline { 2 - 6 } & $\%$ within Capacity & $25.6 \%$ & $61.5 \%$ & $88.1 \%$ & $58.1 \%$ \\
\hline \multirow{2}{*}{ No } & Count & 32 & 15 & 5 & 52 \\
\cline { 2 - 6 } & $\%$ within Capacity & $74.4 \%$ & $38.5 \%$ & $11.9 \%$ & $41.9 \%$ \\
\hline \multirow{2}{*}{ Total } & Count & 43 & 39 & 42 & 124 \\
\cline { 2 - 6 } & $\%$ within Capacity & $100.0 \%$ & $100.0 \%$ & $100.0 \%$ & $100.0 \%$ \\
\hline
\end{tabular}

Chi-Square Tests

\begin{tabular}{|l|l|l|l|}
\hline & Value & Df & $\begin{array}{l}\text { Asymp. Sig. (2- } \\
\text { sided) }\end{array}$ \\
\hline Pearson Chi-Square & $34.382^{\mathrm{a}}$ & 2 & .000 \\
\hline Likelihood Ratio & 37.126 & 2 & .000 \\
\hline Linear-by-Linear Association & 33.864 & 1 & .000 \\
\hline N of Valid Cases & 124 & & \\
\hline
\end{tabular}

Hypothesis 2: Official email Id will have greater impact on communication system of Sugar Factories.

The above table shows the user is having any department wise email ID for internal communication. There is a significant difference of responses for the same Chi-square $=34.382, \mathrm{df}=2, \mathrm{P}=.000$ ). The above statistics shows that total $58.1 \%$ users are agreed where as $41.9 \%$ users are disagreed. However it shows that as compared with large capacity (88.1\%) of Sugar Factories small capacity (25.6\%) are having very less communication on department wise email ID. It might be possible that large Sugar Factories are having confusion in between department wise email ID and their personal ID. Use of official email Id helps to keep track to bridging communication gap and bringing transparency in communication system of Sugar Factories. Therefore hypothesis is accepted.

8. Do you have notices system online for all the stakeholder inside the sugar factory

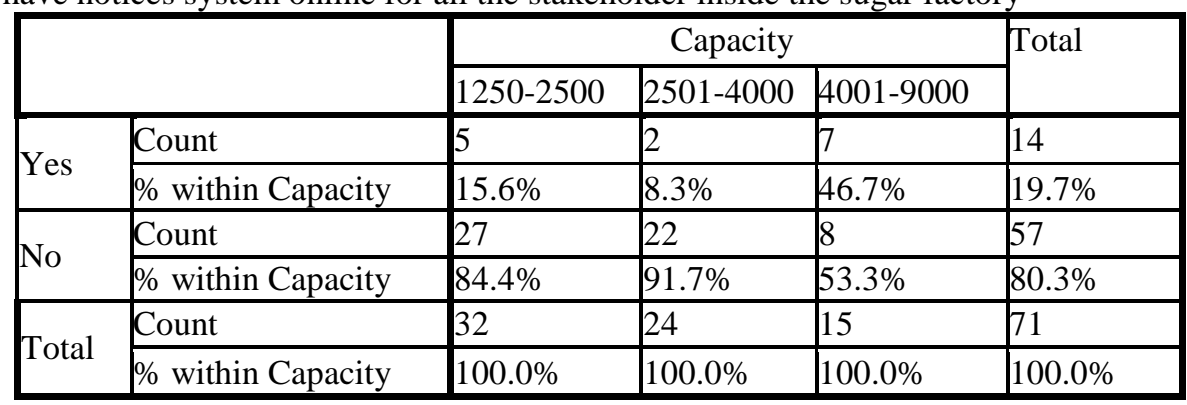

Chi-Square Tests

\begin{tabular}{|l|l|l|l|}
\hline & Value & Df & $\begin{array}{l}\text { Asymp. Sig. (2- } \\
\text { sided) }\end{array}$ \\
\hline Pearson Chi-Square & $9.185^{\mathrm{a}}$ & 2 & .010 \\
\hline Likelihood Ratio & 8.266 & 2 & .016 \\
\hline Linear-by-Linear Association & 4.156 & 1 & .041 \\
\hline N of Valid Cases & 71 & & \\
\hline
\end{tabular}




\section{CONCLUSION}

1. All capacity of Sugar Factories must need to implement computerized system to maintain the events, activities, invitation, meetings \& work schedules.

2. There must be standard solution of SMS operation for all stakeholders.

3. There must be option on web portal of Sugar Industry to publish notices, circulars, minutes of meetings etc. It will help to informational users to get information easily.

4. There must be some system to transmit the information and data from one department to other.

5. Each stakeholder's department wise ID and email tracking system must be exist for bringing transparency and keeping the track over emails. It will also help in bringing transparency in communication system of Sugar Factories.

\section{REFERENCES}

[1]. Dr. B. S. Sawant, Uma Jalindar Yadav "A Case Study: Problems and Prospects of IT Implementation in Sugar Factory”, International Journal of Advanced Research in Computer Science and Software Engineering, Volume 2, Issue 8, August 2012 ISSN: 2277 128X.

[2]. Cecile N. Gerwel Proches (South Africa), Shamim Bodhanya (South Africa), "An analysis of multi-stakeholder interactions in the sugar industry using a social complexity framework", Problems and Perspectives in Management, Volume 11, Issue 4, 2013.

[3]. C.R.Kothari, "Research Methodology Methods \& Techniques", Reprinted $2^{\text {nd }}$ revised Edition, New Age International (P) Ltd., publishers, 2007. 